\title{
Effects of bile duct stricture on the pharmacokinetics of the immunosuppressant tacrolimus in rats
}

\author{
Shinji Kobuchi ${ }^{*}$, Keizo Fukushima ${ }^{2}$, Yuta Maeda' ${ }^{1}$, Takatoshi Kokuhu ${ }^{3}$, Hidetaka Ushigome ${ }^{4}$, Norio Yoshimura ${ }^{4}$, Nobuyuki Sugioka ${ }^{2}$ \\ and Kanji Takada' \\ *Correspondence: ky05122@poppy.kyoto-phu.ac.jp \\ 'Department of Pharmacokinetics, Kyoto Pharmaceutical University, Yamashina-ku, Kyoto 607-8412, Japan. \\ ${ }^{2}$ Department of Clinical Pharmacokinetics, Faculty of Pharmaceutical Sciences, Kobe Gakuin University, 1-1-3 Minatojima, \\ Chuo-ku, Kobe 650-8586, Japan. \\ ${ }^{3}$ Department of Hospital Pharmacy, Kyoto Prefectural University of Medicine, Kamigyou-ku Kyoto, Japan. \\ ${ }^{4}$ Department of Transplantation and Regenerative Surgery, Kyoto Prefectural University of Medicine, Kamigyou-ku Kyoto, Japan.
}

\begin{abstract}
Background: To investigate the effects of bile duct stricture on the pharmacokinetics of the immunosuppressant tacrolimus, the pharmacokinetics of tacrolimus in rats with bile duct ligation were evaluated and the effects of the amount of intestinal bile on intestinal tacrolimus absorption were determined.

Methods: In vivo pharmacokinetic studies and in vitro metabolic studies in rats with bile duct ligation were performed. In addition, an in situ absorption study was performed.

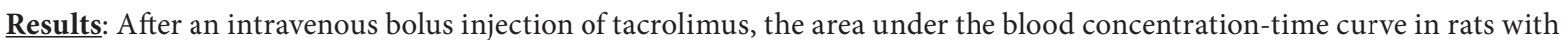
bile duct ligation was approximately 1.9 -fold greater than that in control rats. The total clearance and steady-state volume of distribution decreased in the rats with bile duct ligation by $44.1 \%$ and $40.4 \%$, respectively. Moreover, the production ratios of demethyl-tacrolimus and hydroxy-tacrolimus in the hepatic microsomes of rats with bile duct ligation were $59-62 \%$ and $21-43 \%$, respectively, lower than the corresponding ratios in control rats. The area under the blood concentration-time curve after intraloop administration of tacrolimus with double-diluted bile or with saline was significantly lesser than that with undiluted bile. Significant positive linear correlations were observed between the amount of intestinal bile and the area under the blood concentration-time curve of tacrolimus $(r=0.999, p<0.05)$.

Conclusions: The decrease in the hepatic intrinsic clearance of tacrolimus in rats with bile duct ligation suggests that the bile duct stricture might contribute to the clinically observed inter- and intra-patient pharmacokinetic variability. The amount of bile in the intestine is an important factor that should be considered during tacrolimus treatment. When the route of administration of tacrolimus is changed from injection to an oral one or during long-term oral administration of tacrolimus in patients with bile duct stricture, the decrease in absorption should be taken into account, and the dose should be adjusted accordingly. Taken together, the data indicate that personalized therapy is required for patients with bile duct stricture, and it is necessary to carefully evaluate therapeutic drug monitoring data for tacrolimus.
\end{abstract}

Keywords: Pharmacokinetics, bile ducts, tacrolimus, therapeutic drug monitoring

\section{Introduction}

Tacrolimus (TAC), an immunosuppressive agent (molecular weight of the non-hydrate form, 806), inhibits the signal transduction pathway involved in the activation of T-lymphocytes $[1,2]$.TAC is used for preventing or treating graft rejection after organ transplantation [3], and is superior to cyclosporine (CyA) in improving survival (patient and graft) and preventing acute rejection in living donor liver transplantation patients [4]. TAC is the drug of choice for living donor liver transplant recipients in our university hospital, Kyoto Prefectural University of Medicine. The pharmacokinetics (PK) of TAC are characterized by a marked and unexplained variability, particularly in the early period after transplantation $[5,6]$. TAC is highly lipophilic and insoluble in water, and is a substrate for the drug efflux pump, P-glycoprotein (Pgp), and the metabolizing enzyme, cytochrome P450 (CYP) 3A. These physicochemical properties of TAC contribute to the large variation in oral absorption and extensive metabolic clearance from the body. In addition, TAC has a narrow therapeutic window and thus therapeutic drug monitoring (TDM) is essential for maintaining efficacy $[7,8]$ and minimizing the toxicity of TAC $[9,10]$.

Liver transplantation is a widely accepted treatment for patients with end-stage hepatic disease. Despite improvements in organ preservation technology, surgical technique, and immunosuppressive strategies, postoperative biliary stricture after liver transplantation is still a significant cause of morbidity and mortality [11]. Bile duct anastomotic stricture is a common problem after orthotopic liver transplantation, with an incidence of $15-20 \%$ [12]. Accumulation of bile acids in liver tissue because of biliary obstruction leads to production of free radicals, activation of hepatic stellate cells, and liver fibrosis [13-15]. In addition, cholestasis caused by bile duct ligation

(C) 2013 Kobuchi et al; licensee Herbert Publications Ltd. This is an Open Access article distributed under the terms of Creative Commons Attribution License (http://creativecommons.org/licenses/by/3.0). This permits unrestricted use, distribution, and reproduction in any medium, provided the original work is properly cited. 
Kobuchi et al. Interactive Medicinal Chemistry 2013,

(BDL) induces intestinal bile deficiency and accumulation of biliary compounds in the body [16]. Liver dysfunction or $\mathrm{BDL}$ decreases the availability of bile salts for solubilization of lipid-soluble drugs, and thus the intestinal absorption of TAC might decrease in patients with bile duct stricture. Therefore, we hypothesized that bile duct stricture after liver transplantation may influence the control of blood TAC concentration during TDM as well as the PK of TAC, especially through hepatic metabolism and intestinal absorption. Thus, the aim of our study was to elucidate the effects of BDL and the effects of different concentrations of bile in the intestine on the PK of TAC in rats with BDL.

\section{Methods}

Materials

TAC and CyA, which was used as an internal standard in liquid chromatography-tandem mass spectrometry (LC MS/MS) analysis as described below, were purchased from Sigma-Aldrich Co. (Steinheim, Germany). Propylene glycol was obtained from Wako Pure Chemical Industries (Osaka, Japan). All other reagents were of analytical grade and used without further purification.

\section{Animal preparation}

All experimental protocols involving animals were performed in accordance with the Kyoto Pharmaceutical University Guidelines for Animal Experimentation and approved by the University's Animal Ethics Committee (animal protocol number: 030005). We purchased 10-week-old male Wistar rats (weighing $300 \pm 10 \mathrm{~g}$ ) from Nippon SLC Co., Ltd. (SLC, Hamamatsu, Japan). All rats were housed in a temperaturecontrolled facility with a 12-h light/12-h dark cycle for at least 5 days before use. The animals were fed standard rodent chow. Free access to food and water was allowed before the experiments. In this study, 36 rats were used and divided into 9 groups ( $n=4$ per group). BDL rats were prepared using a previously reported method with some modifications [17]. The animals were anesthetized with an intraperitoneal injection of sodium pentobarbital ( $32 \mathrm{mg} / \mathrm{kg}$ body weight), and BDL was performed through flank incisions; subsequently, the muscle layers and the skin were sutured to close the wound. Sham surgeries were performed in control rats. After surgery, both control and BDL rats had free access to normal rat chow and tap water and were maintained as described above for 3 days. The $B D L$ rats were used in the experiments on the fourth day after surgery. Hepatic function was determined by measuring the levels of total bilirubin (T-bil), glutamic pyruvic transaminase (GPT), glutamic oxaloacetic transaminase (GOT), and alkaline phosphatase (ALP) in both the control and BDL rats at a commercial laboratory, Kyoto BIKEN (Kyoto, Japan) just before the experiment.

\section{PK study of TAC in BDL rats}

The PK of TAC was determined in BDL rats. Control and BDL rats were fasted overnight but had free access to water. The rats were anesthetized using sodium pentobarbital $(32 \mathrm{mg} / \mathrm{kg}$ body weight, intraperitoneal injection) and were placed in the supine position on a heating pad to maintain body temperature during all experiments. The dose of TAC in the PK studies was based on the clinical dose $(0.1-0.3 \mathrm{mg} / \mathrm{kg}$ body weight) and blood concentration profiles observed in the clinical situation (1-50 ng/mL). The solutions of TAC for administration were prepared by dissolving TAC into propylene glycol $(0.1 \mathrm{mg} /$ $\mathrm{mL}$ ). The TAC solution was administered into the right jugular vein of the control $(n=4)$ and BDL rats $(n=4)$ at a dose of 0.1 $\mathrm{mg} / \mathrm{kg}$ body weight ( $1 \mathrm{~mL} / \mathrm{kg}$ of TAC solution). Blood samples $(200 \mu \mathrm{L})$ were drawn from the external left jugular vein into heparinized microcentrifuge tubes at $0.25,0.5,1,2,4$, and 6 $\mathrm{h}$ after drug administration and were immediately frozen at $-80^{\circ} \mathrm{C}$ until analysis.

\section{In vitro metabolic studies using hepatic microsomal fractions from rats}

Metabolism of TAC was measured in a nicotinamide adenine dinucleotide phosphate (NADPH)-generating system according to a previously reported method [18]. Rat livers were rapidly excised and perfused with ice-cold potassium chloride (KCl) solution $(1.15 \% \mathrm{w} / \mathrm{v})$, and hepatic microsomes were prepared by differential ultracentrifugation [19]. Briefly, the rat liver was homogenized in 3 volumes of $1.15 \% \mathrm{w} / \mathrm{v} \mathrm{KCl}$ in a glass-Teflon homogenizer maintained on ice. The homogenates were centrifuged at $4^{\circ} \mathrm{C}$ at $9,000 \times g$ for $15 \mathrm{~min}$, and the supernatants were centrifuged again at $105,000 \times g$ for $1 \mathrm{~h}$. Final microsomal pellets were resuspended in $0.1 \mathrm{M}$ phosphate buffer at a concentration of $1.0 \mathrm{mg}$ protein $/ \mathrm{mL}$. The concentration of protein in the microsomal preparations was determined using the method described by Lowry et al., bovine serum albumin was used as a standard [20]. We prepared and added $50 \mu \mathrm{L}$ of $10 \mathrm{mM}$ NADPH in $0.1 \mathrm{M}$ phosphate buffer ( $\mathrm{pH} 7.4), 50 \mu \mathrm{L}$ of $100 \mathrm{mM}$ glucose 6-phosphate (G6P) in $0.1 \mathrm{M}$ phosphate buffer, $4 \mu \mathrm{L}$ of 500 units of $\mathrm{G} 6 \mathrm{P}$ dehydrogenase in $0.1 \mathrm{M}$ phosphate buffer, $50 \mu \mathrm{L}$ of $100 \mathrm{mM} \mathrm{MgCl}_{2}$ in $0.1 \mathrm{M}$ phosphate buffer, $736 \mu \mathrm{L}$ of $0.1 \mathrm{M}$ phosphate buffer, and $10 \mu \mathrm{L}$ of TAC solution to a clean conical glass tube to produce final concentrations of $2.5,5.0,7.5$, and $10 \mu \mathrm{M}$. After $5 \mathrm{~min}$ of preincubation in a water bath maintained at $37^{\circ} \mathrm{C}$, the metabolic reaction was initiated by adding $100 \mu \mathrm{L}$ of rat liver microsomal suspension (final concentration, $0.8 \mathrm{mg}$ protein $/ \mathrm{mL}$ ). After incubation for $10 \mathrm{~min}$, the reaction was stopped by adding $200 \mu \mathrm{L}$ of icecold $2 \% \mathrm{ZnSO}_{4}$ in $50 \%$ methanol solution. The mixture was vigorously vortexed and centrifuged at $12,000 \times g$ for $10 \mathrm{~min}$ to precipitate the proteins. The resulting supernatant was used for the analysis of TAC metabolites, demethyl-TAC and hydroxy-TAC, and immediately frozen at $-80^{\circ} \mathrm{C}$ until analysis.

\section{In situ TAC absorption study}

To investigate the effect of the amount of intestinal bile on the intestinal absorption of TAC, we performed an in situ 

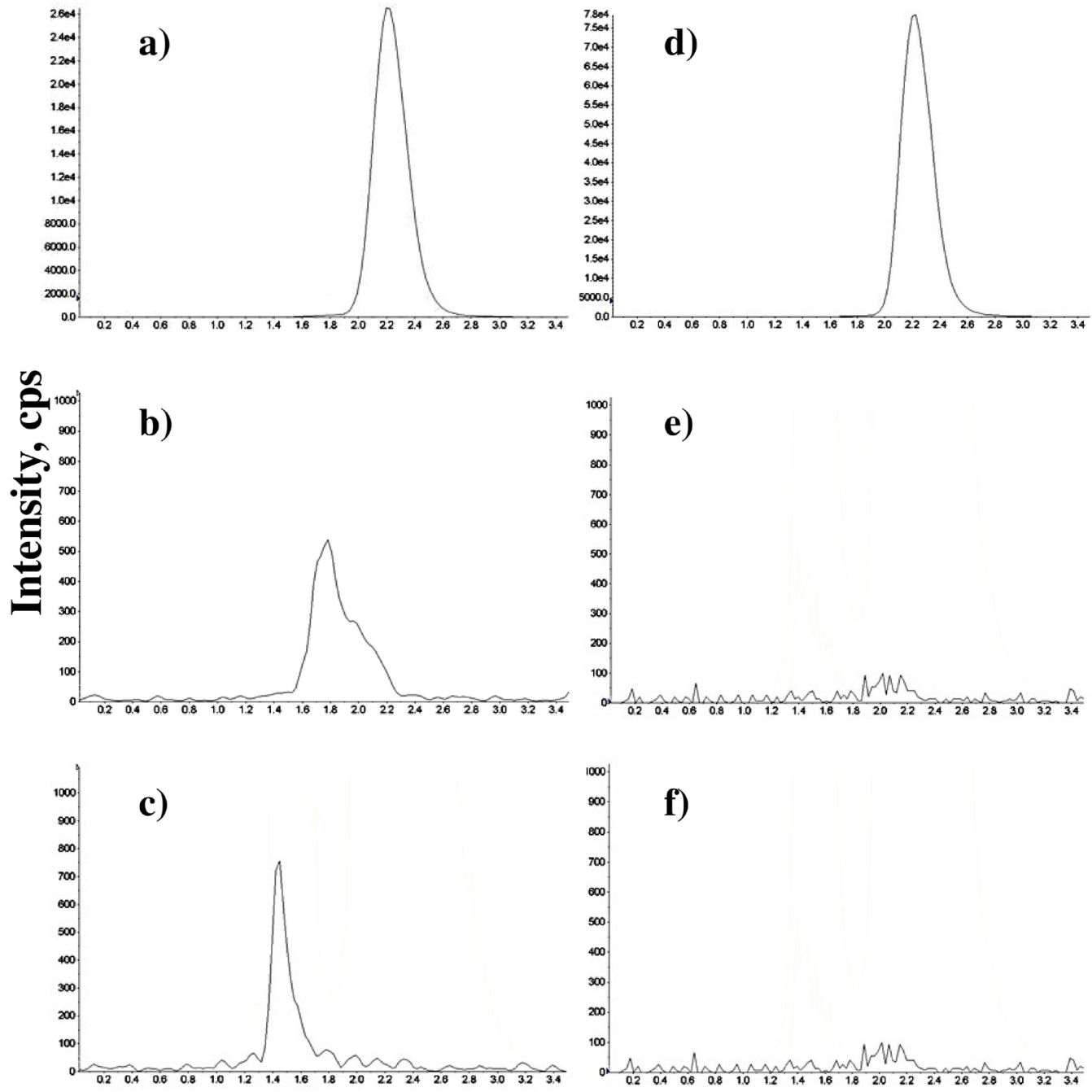

\section{Time (min)}

Figure 1. Typical liquid chromatography tandem mass spectrometry chromatograms of tacrolimus and its metabolites Chromatograms a-c correspond to the extract from hepatic microsomes after incubation for $10 \mathrm{~min}$ in the presence of nicotinamide adenine dinucleotide phosphate (NADPH): (a) tacrolimus (TAC) $(821.50 \rightarrow 769.65 \mathrm{~m} / z)$, (b) demethyl-TAC $(807.50 \rightarrow 755.65 \mathrm{~m} / z)$, (c) hydroxy-TAC $(837.50 \rightarrow 785.65$ $\mathrm{m} / z$ ). Chromatograms $\mathrm{d}-\mathrm{f}$ correspond to the extract from hepatic microsomes after incubation for 10 min in the absence of NADPH: (d) TAC $(821.50 \rightarrow 769.65 \mathrm{~m} / z)$, (e) demethyl-TAC $(807.50 \rightarrow 755.65 \mathrm{~m} / z)$, (f) hydroxy-TAC $(837.50 \rightarrow 785.65 \mathrm{~m} / \mathrm{z})$.

absorption study. Bile was collected from rats and pooled immediately before the experiment. Rats $(n=12)$ were divided into 3 groups ( $n=4$ per group): $A, B$, and C. In all groups, a 20-cm-long segment from the proximal end of the duodenum was surgically looped by placement of inlet and outlet silicon tubes (internal diameter [i.d.], $4.2 \mathrm{~mm}$ ). After the contents of the looped intestine were washed 3 times with $25 \mathrm{mM}$ glucose in phosphate-buffered saline, the solution remaining in the lumen was expelled with air at a rate of $1 \mathrm{~mL} / \mathrm{min}$. A polyethylene cannula (i.d., $0.47 \mathrm{~mm}$ ) was introduced into the portal vein for obtaining blood samples. Then, $0.3 \mathrm{mg} /$ $\mathrm{kg}$ body weight of TAC ( $1 \mathrm{~mL} / \mathrm{kg}$ of TAC solution for the in situ absorption study) and $1.28 \mathrm{~mL} / \mathrm{kg}$ of undiluted bile (group A), $1.28 \mathrm{~mL} / \mathrm{kg}$ of bile diluted with saline to double the volume (group B), or saline (group C) were injected into the looped intestine of each rat. Blood samples $(200 \mu \mathrm{L})$ were collected from the portal vein into heparinized microcentrifuge tubes $0.083,0.25,0.5,0.75,1,1.5$, and $2 \mathrm{~h}$ after drug administration and immediately frozen at $-80^{\circ} \mathrm{C}$ until analysis.

\section{Assay procedures using LC-MS/MS}

Analysis of TAC levels in the blood and the level of demethyl- 
Kobuchi et al. Interactive Medicinal Chemistry 2013,

http://www.hoajonline.com/journals/pdf/2053-7107-1-1.pdf

doi: 10.7243/2053-7107-1-1

Table 1. Body weights and hepatic function in control rats and rats with bile duct ligation.

\begin{tabular}{llllllll}
\hline & \multicolumn{3}{c}{ Control rats } & \multicolumn{3}{c}{ BDL rats } \\
\hline Body weight (g) & 288.8 & \pm & 3.4 & 280.5 & \pm & 2.7 \\
T-bil (mg/dL) & 0.20 & \pm & 0.00 & 4.88 & \pm & $1.22^{* *}$ \\
GPT (IU/L) & 107.3 & \pm & 18.5 & 900.5 & \pm & $178.6^{* *}$ \\
GOT (IU/L) & 228.5 & \pm & 16.3 & 1641.3 & \pm & $511.2^{* *}$ \\
ALP (IU/L) & 353.5 & \pm & 49.8 & 1367.8 & \pm & $243.8^{* *}$ \\
\hline
\end{tabular}

T-bil, total bilirubin; GPT, glutamic pyruvic transaminase; GOT, glutamic oxaloacetic transaminase; ALP, alkaline phosphatase; BDL, bile duct ligation

Each value represents the mean \pm standard error (S.E.) of 4 rats.

${ }^{* *} p<0.01$ statistically different from control in unpaired Student's $t$-tests

TAC and hydroxy-TAC in the hepatic microsomes was performed using LC-MS/MS [21]. The LC-MS/MS system (Applied Biosystems, Foster City, California) consisted of an LC-10AD micropump (Shimadzu Corporation, Kyoto, Japan) and an AS8020 automatic sample injector (Toso, Tokyo, Japan). MS was performed in the positive-ion electrospray ionization (ESI) mode. CyA was used as the internal standard. LC-MS/MS analyses were performed using Quicksorb ODS $(2.1 \mathrm{~mm} \times 150$ $\mathrm{mm}, 5 \mu \mathrm{m}$; Chemco Scientific Co. Ltd., Osaka, Japan) maintained at $60^{\circ} \mathrm{C}$ for all separations. The mobile phase consisted of 10 $\mathrm{mM}$ ammonium acetate/acetonitrile $(10: 90 \mathrm{v} / \mathrm{v})$ at a flow rate of $0.2 \mathrm{~mL} / \mathrm{min}$. The ion spray voltage and temperature were set at $5000 \mathrm{~V}$ and $300^{\circ} \mathrm{C}$, respectively. The flow rates of the nebulizer gas, curtain gas, and collision gas were set at 15 , 12 , and $2.0 \mathrm{~L} / \mathrm{min}$, respectively. Multiple reaction monitoring analysis was performed with transition $\mathrm{m} / \mathrm{z} 821.5 \rightarrow 769.7$ for TAC and $m / z \quad 1202.8 \rightarrow 425.2$ for CyA. We measured the levels of 2 metabolites of TAC, demethyl-TAC and hydroxy-TAC, in hepatic microsomes fortified with NADPH with transition $\mathrm{m} / \mathrm{z} 807.5 \rightarrow 755.7$ for demethyl-TAC and $\mathrm{m} / \mathrm{z} 837.5 \rightarrow 785.7$ for hydroxy-TAC. We confirmed the presence of 2 metabolites in hepatic microsomes after incubation for $10 \mathrm{~min}$ with NADPH, whereas these 2 metabolites were not observed in the hepatic microsomes after incubation without NADPH for $10 \mathrm{~min}$ (Figure 1). Standard samples were prepared by adding aliquots of TAC stock solutions to a drug-free matrix. The solid-phase extraction cartridge (Oasis ${ }^{\circledR}$ HLB; Waters Corp., Massachusetts, USA) was activated using $1 \mathrm{~mL}$ of acetonitrile followed by 1 $\mathrm{mL}$ of ion-exchanged water to prepare the solvent for use. Standard and unknown samples $(100 \mu \mathrm{L})$ were added to 10 $\mu \mathrm{L}$ of the internal standard (CyA, $200 \mu \mathrm{g} / \mathrm{mL}$ in methanol) and $100 \mu \mathrm{L}$ of $2 \% \mathrm{ZnSO}_{4}$ in $50 \%$ methanol solution, and the tube was vigorously vortexed for $15 \mathrm{~s}$. After centrifugation for $5 \mathrm{~min}$ at $12,000 \times g$, the supernatant was applied to the solid-phase extraction cartridges and subsequently washed with $2 \mathrm{~mL}$ of ion-exchanged water. A $1.5 \mathrm{~mL}$ clean tube was positioned below the solid-phase extraction cartridges, and the compounds were eluted with $1 \mathrm{~mL}$ of acetonitrile. The eluate was dried under nitrogen at $37^{\circ} \mathrm{C}$. The residue was redissolved with $100 \mu \mathrm{L}$ of the mobile phase, and 50 $\mu \mathrm{L}$ was injected into the LC-MS/MS system for analysis.

\section{PK analysis}

Standard PK parameters were calculated from the blood concentration-time curve of TAC by using noncompartmental PK analysis using WinNonlin Version 6.3 (Pharsight Co., Mountain View, CA). The terminal slope $\left(\lambda_{z}\right)$ was determined using linear regression of at least 3 data points from the terminal portion of the blood concentration-time curve. The area under the blood concentration-time curve, extending from 0 to the last point measured ( $A \cup C_{0 \text {-las }}$ ), was calculated using the linear trapezoidal rule up to the last blood concentration measured $\left(C_{\text {bllast })}\right)$. The area under the blood concentrationtime curve, extending from 0 to infinity $\left(A \cup C_{0-\infty}\right)$, was extrapolated to infinity using a correction term, namely, $C_{b(\text { last })} \lambda_{z}$. The elimination half-life $\left(t_{1 / 2}\right)$ was calculated using the equation $t_{1 / 2}=\ln 2 / \lambda_{z}$. The area under the firstmoment curve from 0 to infinity $(A U M C)$ was calculated using the linear trapezoidal rule and the addition of the concentration term after the last measured point $\left(t_{\text {[last] }}\right)$ to infinity, namely, $t_{\text {(last) }} C_{\text {bllast) }} / \lambda_{z}+C_{\text {bllast) }} / \lambda_{z}{ }^{2}$. The mean residence time (MRT) was calculated using $A U M C / A \cup C_{0-\infty}$ Total blood clearance $\left(C_{\text {tot }}\right)$ was calculated using $D / A U C_{0}$ ${ }_{\infty}$ in which $D$ represents the TAC dose administered. The steady-state volume of distribution $\left(V d_{s s}\right)$ was calculated by multiplying $C_{\text {tot }}$ with $M R T$.

\section{Statistical analysis}

All values are expressed as mean \pm standard error (S.E.). The 2 groups were compared using Student's unpaired $t$-test. Correlations between the amount of bile in the intestinal loop and $A \cup C_{0-2}$ of TAC after intraloop administration were assessed statistically using Pearson's correlation coefficient test. The differences between the means were considered statistically significant when $p<0.05$.

\section{Results}

\section{Biochemical parameters in BDL rats}

The biochemical parameters of the control and BDL rats are shown in Table 1. No significant differences were observed in body weights between control and BDL rats. The level of T-bil in BDL rats was approximately 22-fold higher than that in control rats. Furthermore, the levels of GPT, GOT, and ALP were significantly higher in BDL rats than in control rats.

\section{$P K$ analysis of TAC in BDL rats}

The mean blood TAC concentration-time curves after administration of an intravenous (i.v.) bolus injection of TAC to BDL rats are shown in Figure 2; the PK parameters of 
Kobuchi et al. Interactive Medicinal Chemistry 2013,

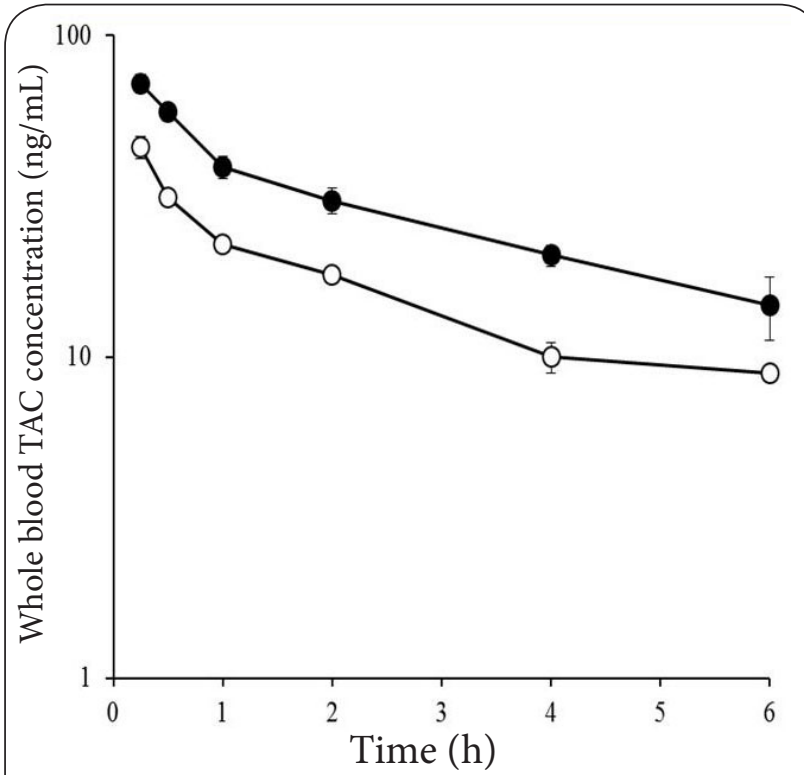

Figure 2. Mean whole blood concentration profiles of tacrolimus (TAC) after intravenous administration of $0.1 \mathrm{mg} / \mathrm{kg}$ body weight TAC to control rats and rats with bile duct ligation $\left({ }^{\circ}\right)$ Control rats; $(\bullet)$ Bile duct ligation $(\mathrm{BDL})$ rats. Data are presented as the mean \pm standard error (S.E.) of 4 rats.

Table 2. Pharmacokinetic parameters after intravenous administration of tacrolimus $(0.1 \mathrm{mg} / \mathrm{kg}$ body weight $)$ to control rats and rats with bile duct ligation.

\begin{tabular}{lllllll}
\hline $\begin{array}{l}\text { Pharmacokinetic } \\
\text { parameters }\end{array}$ & \multicolumn{3}{c}{ Control rats } & \multicolumn{3}{c}{ BDL rats } \\
\hline$t_{1 / 2}(\mathrm{~h})$ & 3.91 & \pm & 0.12 & 4.31 & \pm & 1.03 \\
$C L_{\text {tot }}(\mathrm{L} / \mathrm{h} / \mathrm{kg})$ & 0.67 & \pm & 0.01 & 0.38 & \pm & $0.06^{*}$ \\
$V d_{\text {ss }}(\mathrm{L} / \mathrm{kg})$ & 3.32 & \pm & 0.13 & 1.98 & \pm & $0.31^{* *}$ \\
$A U C_{0-\infty}(\mathrm{ng} \cdot \mathrm{h} / \mathrm{mL})$ & 150.0 & \pm & 2.8 & 280.2 & \pm & $32.9^{*}$ \\
\hline
\end{tabular}

Each value represents the mean \pm standard error (S.E.) of 4 rats.

${ }^{* *} p<0.01,{ }^{*} p<0.05$ significantly different from control in unpaired Student's $t$-tests BDL, bile duct ligation; $t_{1 / 2}$, elimination half-life; $C L_{\text {tor }}$, total blood clearance; $V d s s$, steady-state volume of distribution; $A U C_{0-\infty}$, area under the blood concentration-time curve, extending from 0 to infinity

TAC observed for each group are shown Table 2. After i.v. bolus injections of TAC, the $A U C_{0-\infty}$ in BDL rats was approximately 1.9-fold greater than that in control rats. $C L_{\text {tot }}$ and $V d_{s s}$ were significantly lower in BDL rats than in control rats by $44.1 \%$ and $40.4 \%$, respectively.

Metabolism of TAC in hepatic microsomes of BDL rats The ratios of production of demethyl-TAC and hydroxy-TAC in the hepatic microsomes from BDL rats and control rats are shown in Figure $\mathbf{3} \mathbf{a}$ and $\mathbf{3} \mathbf{b}$, respectively. The production ratios of demethyl-TAC and hydroxy-TAC in hepatic microsomes
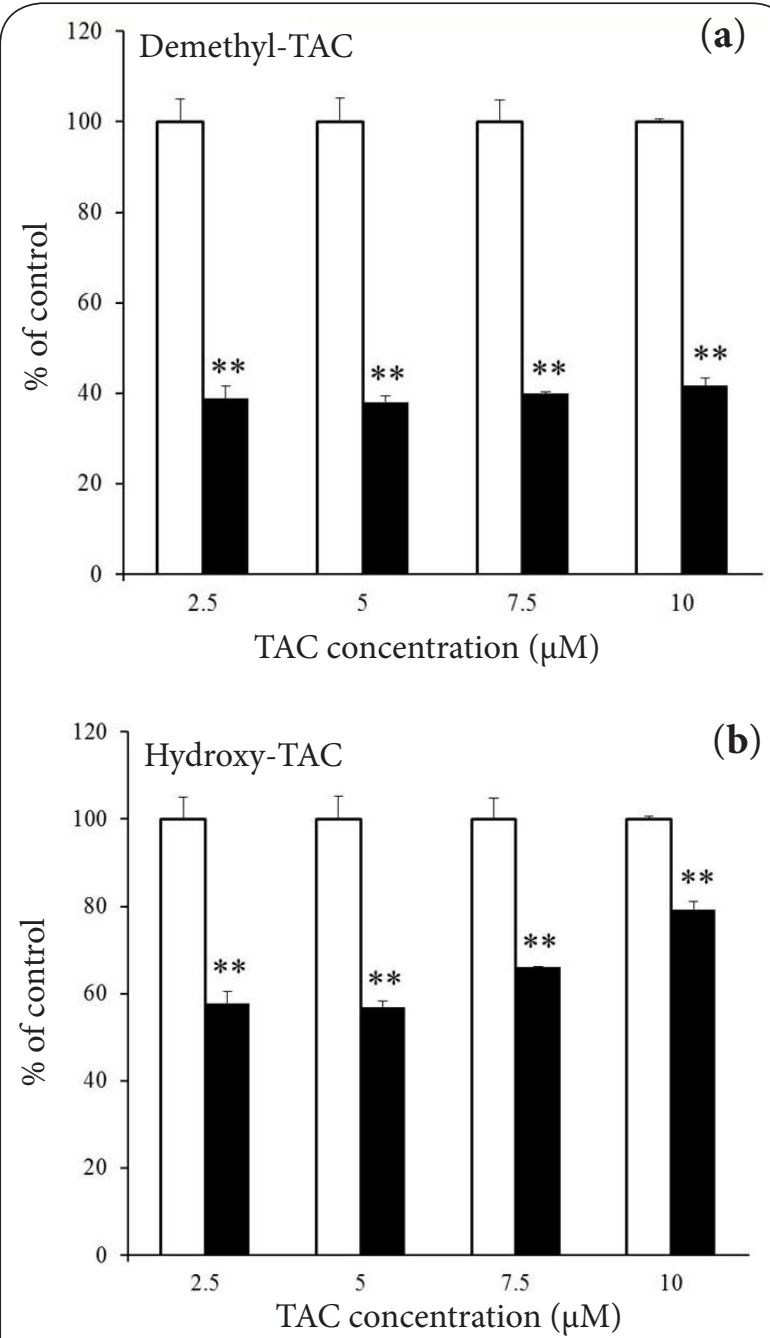

Figure 3. Metabolic studies of tacrolimus with hepatic microsomes from control rats and rats with bile duct ligation. Production ratio of demethyltacrolimus (TAC) (a) and hydroxy-TAC (b) in the microsomes of rats with bile duct ligation (BDL) versus that in control rats. ( $\square$ ) Control rats and (-) BDL rats. Each column with a bar represents the mean \pm standard error (S.E.) of 4 experiments. ${ }^{* *} p<0.01$ significantly different from control rats in unpaired Student's t-tests. from $B D L$ rats were $59-62 \%$ and $21-43 \%$, respectively, lower than the corresponding ratios in control rats.

\section{Effects of bile on the intestinal absorption of TAC} The mean whole blood concentration-time curves of TAC after intraloop administration of TAC with undiluted bile, doublediluted bile, or saline are shown in Figure 4a. The $A U C_{0-2}$ of TAC after intraloop administration of TAC with double-diluted bile or with saline was significantly lower than that with undiluted bile. Significant positive linear correlations were observed between the amount of bile in the intestinal loop and the 

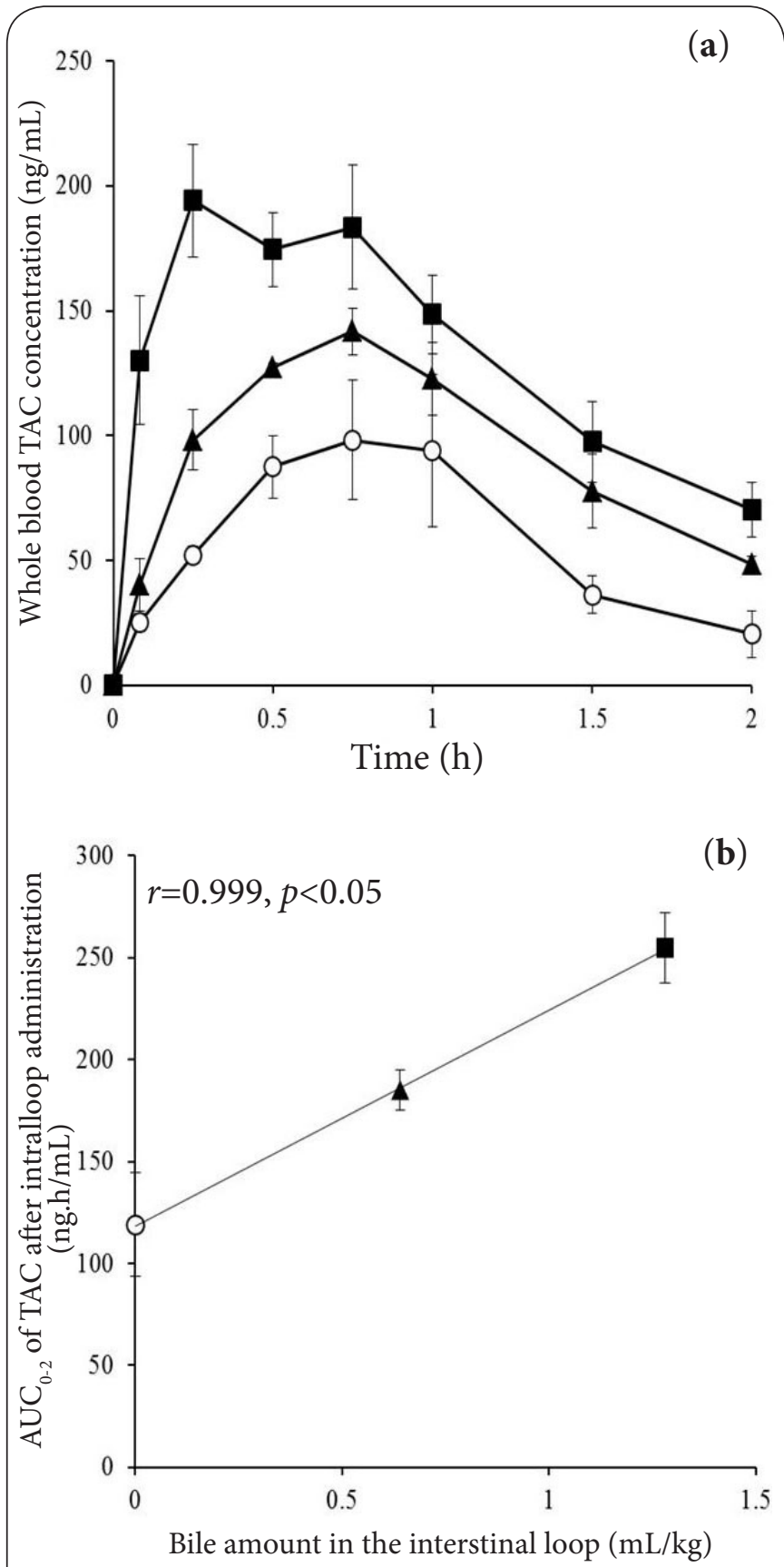

Figure 4. Whole blood concentration-time curves of tacrolimus (TAC) after intraloop administration of TAC with undiluted bile, double-diluted bile, or saline (a), and the correlation between the amount of bile in the intestinal loop and area under the concentration-time curve $\left(A U C_{0-2}\right)$ of TAC after intraloop administration (b), (-) Group A, 0.3 $\mathrm{mg} / \mathrm{kg}$ body weight of TAC $(1 \mathrm{~mL} / \mathrm{kg}$ of TAC solution for in situ absorption study) and $1.28 \mathrm{~mL} / \mathrm{kg}$ of undiluted bile; ( $\Delta$ ) Group B, $0.3 \mathrm{mg} / \mathrm{kg}$ body weight of TAC $(1 \mathrm{~mL} / \mathrm{kg}$ of TAC solution for in situ absorption study) and $1.28 \mathrm{~mL} /$ $\mathrm{kg}$ of double-diluted bile with saline; ( $\left.{ }^{\circ}\right)$ Group C, $0.3 \mathrm{mg} /$ $\mathrm{kg}$ body weight of TAC $(1 \mathrm{ml} / \mathrm{kg}$ of TAC solution for in situ absorption study) and saline. Results are presented as the mean \pm standard error (S.E.) of 3-4 rats.
$A \cup C_{0-2}$ of TAC $(r=0.999, p<0.05 ;$ Figure 4b).

\section{Discussion}

$\mathrm{BDL}$ is an effective and a widely used method for the induction of liver cirrhosis in rats [22-24]. BDL stimulates the proliferation of biliary epithelial cells and oval cells, which are hepatocyte progenitors, and thus result in the proliferation of biliary ductules with accompanying portal inflammation and fibrosis [25]. Thus, the BDL rat model is a well-established, well-received, and widely used model of experimental bile duct stricture. For example, Espinosa et al., performed PK studies of ketorolac, a nonsteroidal anti-inflammatory agent, using BDL rats [26]. In this study, although no significant differences were observed in the body weight, the levels of GPT, GOT, $A L P$, and T-bil in BDL rats were significantly different from the corresponding levels in the control rats (Table 1). Our results are consistent with those reported in previous studies. Ji et al., and Fursule et al., reported that while BDL increased the levels of GPT, GOT, and ALP and the level of T-bil in the serum of $\mathrm{BDL}$ rats, no significant difference was observed in the body weights between the control and $\mathrm{BDL}$ rats throughout the experimental period $[\mathbf{2 7}, \mathbf{2 8}]$. These observations suggested the usefulness of $B D L$ for inducing bile duct stricture in rats to investigate the effects of BDL on the PK of TAC.

Our results indicated that compared to control rats, the $B D L$ rats showed alteration in the PK of TAC. Administration of an i.v. bolus injection of TAC to BDL rats increased the $A \cup C_{0-\infty}$ and decreased the $C L_{\text {tot }}$ (Table 2). We measured the production ratio of demethyl- and hydroxy-TAC in the hepatic microsomes of BDL rats, because the main metabolite of TAC in the blood and urine of patients with a liver graft is demethyl-TAC, whereas the main metabolite of TAC in the bile is hydroxy-TAC [29]. Analysis of the enzyme kinetics of TAC in hepatic microsomes showed that the production ratios of both demethyl- and hydroxy-TAC were significantly lower in the $\mathrm{BDL}$ rats than in the controls, which indicates that the intrinsic clearance $\left(C L_{i n t}\right)$ of TAC in the liver reduced in the BDL rats (Figure 3). Bastien et al., reported that BDL resulted in biliary cirrhosis with a reduction in the liver protein content and the activity of CYP3A, a primary metabolic enzyme of TAC [30]. Sasa et al., estimated the hepatic extraction ratio $\left(E_{h}\right)$ of TAC using a physiologically based PK model [31]. The authors concluded that TAC could be considered as an intermediate hepatic extraction drug, and that $C L_{\text {tot }}$ and $E_{h}$ of TAC depend on both the hepatic blood flow and $C L_{\text {int }}$ in the liver. Moreover, previously studies showed that the hepatic blood flow and hepatic arterial plasma flow increased in BDL rats [31,32]. On the basis of these findings, we can conclude that the decrease in the $C L_{\text {tot }}$ in $\mathrm{BDL}$ rats occurs through a decrease in the $C L_{\text {int }}$ induced by the decrease in hepatic CYP activity, which results in an increase in the $A U C_{0-\infty}$ and blood TAC concentration. Some studies have shown that the AUC values are important determiners for the clinical outcome and side effects of TAC. For example, the AUC values of TAC were significantly lower 
in patients with acute rejection than in patients who had no acute rejection $[33,34]$. These observations suggest that the decrease in the $\mathrm{CL}_{\text {int }}$ of TAC during BDL would contribute to the inter- and intra-patient pharmacokinetic variability. Therefore, TDM should be performed, and the results of TDM should be carefully monitored in patients with bile duct stricture.

As shown in Table 2, $V d_{s s}$ after an i.v. bolus injection of TAC in $\mathrm{BDL}$ rats was approximately half of that in control rats. In addition, the blood concentration of TAC at $15 \mathrm{~min}$ after an i.v. bolus injection in $B D L$ rats $(70.1 \pm 4.8 \mathrm{ng} / \mathrm{mL})$ during the distribution phase was approximately 1.6-times higher than that in control rats $(44.9 \pm 3.7 \mathrm{ng} / \mathrm{ml}$ ) (Figure 2). These findings clearly indicate that distribution of TAC from the systemic circulation to peripheral or central tissues is limited. Hyogo et al., examined the expression of hepatic adenosine triphosphatebinding cassette $(A B C)$ transport proteins and their mRNA levels in canalicular membrane vesicles isolated from rat liver after BDL and observed a clear increase in the mRNA expression levels of multiple drug resistance-Pgp (MDR-Pgp) and MDR1b [35]. In addition, oxidative stress was observed in the blood, liver, intestine, kidney, and brain of BDL rats [36,37]. The findings of our previous studies indicate that oxidative stress-induced impairments may affect the affinity of lipophilic drugs (binding or penetrating) for erythrocyte membranes and thus increase the drug distribution to erythrocytes in a rat model of ferric-nitrilotriacetate-induced oxidative stress [38-40]. Thus, although the liver is a highly perfused organ, the increase in Pgp-mediated excretion of TAC and increase in TAC distribution to erythrocytes in BDL rats may limit TAC distribution to the liver, peripheral, or central tissues and thus decrease the $V d_{s s}$ and increase the blood TAC concentration. Although blood TAC concentrations are high after bile duct stricture, the pharmacological effects of the drug are not changed because TAC does not reach the intended targets in the tissues. Moreover, the limited distribution to the liver in $\mathrm{BDL}$ rats might contribute to reduced hepatic metabolism, which decreases the $C L_{\text {tot }}$ as described above. However, because we did not determine TAC distribution in the blood compartment and in the liver, peripheral, or central tissues in $\mathrm{BDL}$ rats, further studies are required to completely elucidate the alterations in TAC distribution in BDL rats.

Bile acids, such as ursodeoxycholic acid and chenodeoxycholic acid, may lead to formation of micelles with lipophilic drugs such as TAC and consequently enhance their absorption from the gastrointestinal tract [41]. To investigate the influence of reduction in the amount of intestinal bile on the intestinal absorption of TAC in bile duct stricture, we performed an in situ absorption study. We examined the total intestinal permeability using in situ intraloop administration rather than oral or enteral administration, because the former method excludes the effects of gastric acid and gastrointestinal motility. Since TAC is well absorbed from the upper section of the small intestine [42], we performed the in situ absorption study using the upper section of the small intestine. The bile dose administered into the intestine (1.28 $\mathrm{mL} / \mathrm{kg}$ ) was based on the previously reported value of bile flow in rats $(3.2 \mathrm{~mL} / \mathrm{h} / \mathrm{kg})$ [43] and the blood sampling time of $2 \mathrm{~h}$. Upon intraloop administration of TAC with undiluted bile, double-diluted bile, or saline, the $A U C_{0-2}$ of TAC showed a positive correlation with the amount of bile (Figure 4 and Table 2). Sauer et al., reported that after BDL, the intestinal absorption rate of a bile acid taurocholate reduced and that the intestinal absorption of bile acids appears to be regulated by their systemic concentration [44]. Bile is necessary for solubilizing $C y A$, and a lack of bile after $B D L$ decreases the CyA absorption $[45,46]$. These results are consistent with our suggestion that the intestinal absorption of TAC depends on the amount of bile in the intestine, and the lack of bile after BDL may result in decreased TAC absorption. Clinically, biliary drainage in patients receiving living donor liver transplantation plays an important role in the prevention of biliary anastomotic complications and the treatment of biliary anastomotic stenosis. When biliary drainage is performed at Kyoto Prefectural University of Medicine, half of the bile excreted from the drain is returned into the intestinal tract while the remaining half is discarded, which may decrease the TAC absorption and thus the blood TAC concentrations. In a related study, Deters et al., reported that daily treatment with TAC for 2 weeks reduced the bile flow [47]. This decrease in bile flow may reduce TAC absorption. Our findings are similar to those reported previously in that the amount of bile in the intestine is an important factor in TAC treatment. When the TAC formulation is changed from an injectable formulation to an oral one or during long-term oral administration of TAC in patients with bile duct stricture, the decrease in TAC absorption should be considered and the dose of TAC should be appropriately adjusted.

The findings of our study suggest that personalized treatment is required for patients with bile duct stricture, and the TDM data should be carefully examined. However, our study has a limitation. The BDL rat model does not completely represent the complexity associated with the human disease nor does it replace the studies performed using human tissues. However, the model is a valuable tool for developing and evaluating a variety of novel immunosuppressants or emerging therapeutic strategies that are difficult to address in humans.

\section{Conclusions}

In conclusion, $B D L$ decreased the hepatic $C L_{\text {int }}$ of TAC, and this decrease could contribute to the clinically observed interand intra-patient pharmacokinetic variability. This suggests that personalized treatment and careful examination of the TDM data are required in patients with bile duct stricture. Increase in the Pgp-mediated excretion of TAC in the liver and increase in the distribution of TAC to erythrocytes in $\mathrm{BDL}$ rats might limit TAC distribution to the liver, peripheral, or central 
Kobuchi et al. Interactive Medicinal Chemistry 2013,

http://www.hoajonline.com/journals/pdf/2053-7107-1-1.pdf

doi: 10.7243/2053-7107-1-1

tissues and thus decrease the $V d_{s s}$ and increase in the blood TAC concentration. Although the blood TAC concentrations are high after bile duct stricture, the pharmacological effects of the drug are unchanged because TAC does not reach the intended targets in the tissues. This limited distribution to the liver in BDL rats might contribute to a decrease in hepatic metabolism and thus a decrease in $\mathrm{CL}_{\text {tot }}$. Our findings suggest that the amount of bile in the intestine is an important factor in TAC treatment. Therefore, when switching from an injectable formulation of TAC to an oral one or during long-term oral administration of TAC in patients with bile duct stricture, the decrease in absorption and hepatic drug metabolism should be taken into account, and the dose of TAC should be accordingly adjusted.

\section{Competing interests}

The authors declare that they have no competing interests.

Authors' contributions

\begin{tabular}{|l|l|l|l|l|l|l|l|l|}
\hline Authors' contributions & SK & KF & YM & TK & HU & NY & NS & KT \\
\hline Research concept and design & $\sqrt{ }$ & $\sqrt{ }$ & $\sqrt{ }$ & $\sqrt{ }$ & $\sqrt{ }$ & $\sqrt{ }$ & $\sqrt{ }$ & $\sqrt{ }$ \\
\hline Collection and/or assembly of data & -- & -- & $\sqrt{ }$ & $\sqrt{ }$ & $\sqrt{ }$ & $\sqrt{ }$ & $\sqrt{ }$ & -- \\
\hline Data analysis and interpretation & $\sqrt{ }$ & $\sqrt{ }$ & $\sqrt{ }$ & $\sqrt{ }$ & $\sqrt{ }$ & $\sqrt{ }$ & $\sqrt{ }$ & $\sqrt{ }$ \\
\hline Writing the article & $\sqrt{ }$ & $\sqrt{ }$ & $\sqrt{ }$ & -- & -- & -- & $\sqrt{ }$ & -- \\
\hline Critical revision of the article & $\sqrt{ }$ & $\sqrt{ }$ & -- & -- & -- & -- & $\sqrt{ }$ & -- \\
\hline Final approval of article & $\sqrt{ }$ & $\sqrt{ }$ & $\sqrt{ }$ & $\sqrt{ }$ & $\sqrt{ }$ & $\sqrt{ }$ & $\sqrt{ }$ & $\sqrt{ }$ \\
\hline Statistical analysis & $\sqrt{ }$ & $\sqrt{ }$ & $\sqrt{ }$ & -- & -- & -- & $\sqrt{ }$ & -- \\
\hline Other (please specify)... & -- & -- & -- & -- & -- & -- & -- & -- \\
\hline
\end{tabular}

\section{Acknowledgement}

This research received no specific grant from any funding agency in the public, commercial, or not-for-profit sectors. Editorial assistance was provided by Editage, a division of Cactus Communications, Tokyo, Japan .

Publication history

Editors: Oliver Grundmann, University of Florida, USA.

Dong Xiao, University of Pittsburgh School of Medicine, USA.

Received: 08-Jul-2013 Revised: 19-Aug-2013

Accepted: 27-Aug-2013 Published: 10-Sep-2013

\section{References}

1. Kino T, Hatanaka H, Hashimoto M, Nishiyama M, Goto T, Okuhara M, Kohsaka M, Aoki H and Imanaka H. FK-506, a novel immunosuppressant isolated from a Streptomyces. I. Fermentation, isolation, and physicochemical and biological characteristics. J Antibiot (Tokyo). 1987; 40:1249-55. | Article | PubMed

2. Kino T, Hatanaka H, Miyata S, Inamura N, Nishiyama M, Yajima T, Goto T, Okuhara M, Kohsaka M, Aoki H and et al. FK-506, a novel immunosuppressant isolated from a Streptomyces. II. Immunosuppressive effect of FK-506 in vitro. J Antibiot (Tokyo). 1987; 40:1256-65. | Article I PubMed

3. Plosker GL and Foster RH. Tacrolimus: a further update of its pharmacology and therapeutic use in the management of organ transplantation. Drugs. 2000; 59:323-89. | Article | PubMed

4. Haddad EM, McAlister VC, Renouf E, Malthaner R, Kjaer MS and Gluud LL. Cyclosporin versus tacrolimus for liver transplanted patients. Cochrane Database Syst Rev. 2006; 4:CD005161. I Article I PubMed

5. Staatz CE and Tett SE. Clinical pharmacokinetics and pharmacodynamics of tacrolimus in solid organ transplantation. Clin Pharmacokinet. 2004;
43:623-53. | Article | PubMed

6. Naesens M, Kuypers DR and Sarwal M. Calcineurin inhibitor nephrotoxicity. Clin J Am Soc Nephrol. 2009; 4:481-508. | Article | PubMed

7. Kershner RP and Fitzsimmons WE. Relationship of FK506 whole blood concentrations and efficacy and toxicity after liver and kidney transplantation. Transplantation. 1996; 62:920-6. I Article I PubMed

8. McMaster P, Mirza DF, Ismail T, Vennarecci G, Patapis P and Mayer AD. Therapeutic drug monitoring of tacrolimus in clinical transplantation. Ther Drug Monit. 1995; 17:602-5. I Article I PubMed

9. Boswell GW, Bekersky I, Fay J, Wingard J, Antin J, Weisdorf D, Maher R, Fitzsimmons W and Nash R. Tacrolimus pharmacokinetics in BMT patients. Bone Marrow Transplant. 1998; 21:23-8. I Article I PubMed

10. Jusko WJ, Piekoszewski W, Klintmalm GB, Shaefer MS, Hebert MF, Piergies AA, Lee CC, Schechter P and Mekki QA. Pharmacokinetics of tacrolimus in liver transplant patients. Clin Pharmacol Ther. 1995; 57:281-90. | Article I PubMed

11. Stratta RJ, Wood RP, Langnas AN, Hollins RR, Bruder KJ, Donovan JP, Burnett DA, Lieberman RP, Lund GB, Pillen TJ and et al. Diagnosis and treatment of biliary tract complications after orthotopic liver transplantation. Surgery. 1989; 106:675-83. I PubMed

12. Ostroff JW. Post-transplant biliary problems. Gastrointest Endosc Clin N Am. 2001; 11:163-83. | Article | PubMed

13. Sokol RJ, Devereaux M, Khandwala R and O'Brien K. Evidence for involvement of oxygen free radicals in bile acid toxicity to isolated rat hepatocytes. Hepatology. 1993; 17:869-81. | Article | PubMed

14. Poli G. Pathogenesis of liver fibrosis: role of oxidative stress. $\mathrm{Mol}$ Aspects Med. 2000; 21:49-98. | Article | PubMed

15. Tahan G, Akin H, Aydogan F, Ramadan SS, Yapicier O, Tarcin O, Uzun H Tahan $\mathrm{V}$ and Zengin K. Melatonin ameliorates liver fibrosis induced by bile-duct ligation in rats. Can J Surg. 2010; 53:313-8. | Pdf | PubMed Abstract | PubMed Full Text

16. Minich DM, Havinga R, Stellaard F, Vonk RJ, Kuipers F and Verkade HJ. Intestinal absorption and postabsorptive metabolism of linoleic acid in rats with short-term bile duct ligation. Am J Physiol Gastrointest Liver Physiol. 2000; 279:G1242-8. | Article | PubMed

17. Sanchez-Patan F, Anchuelo R, Corcuera MT, Casado I, Gomez-Aguado F, Aller MA, Cruz A, Alonso MJ and Arias J. Biliary fibrosis in microsurgical extrahepatic cholestasis in the rat. Microsurgery. 2008; 28:361-6. Article I PubMed

18. Sugioka N, Sato K, Haraya K, Maeda Y, Yasuda K, Fukushima K, Ito Y and Takada K. Effect of streptozotocin-induced diabetes mellitus on the pharmacokinetics of nelfinavir in rats. Biopharm Drug Dispos. 2008; 29:469-79. | Article | PubMed

19. Hayes KA, Brennan B, Chenery R and Houston JB. In vivo disposition of caffeine predicted from hepatic microsomal and hepatocyte data. Drug Metab Dispos. 1995; 23:349-53. | Article I PubMed

20. Lowry OH, Rosebrough NJ, Farr AL and Randall RJ. Protein measurement with the Folin phenol reagent. J Biol Chem. 1951; 193:265-75. | Article | PubMed

21. Koster RA, Dijkers EC and Uges DR. Robust, high-throughput LC-MS/MS method for therapeutic drug monitoring of cyclosporine, tacrolimus, everolimus, and sirolimus in whole blood. Ther Drug Monit. 2009; 31:116-25. | Article | PubMed

22. Maya-Mendoza A, Hernandez-Munoz R, Gariglio P and Aranda-Anzaldo A. Gene positional changes relative to the nuclear substructure during carbon tetrachloride-induced hepatic fibrosis in rats. J Cell Biochem. 2004; 93:1084-98. | Article | PubMed

23. Mikami K, Otaka M, Goto T, Miura K, Ohshima S, Yoneyama K, Lin JG, Watanabe D, Segawa D, Kataoka E, Odashima M and Watanabe $\mathrm{S}$. Induction of a 72-kDa heat shock protein and protection against lipopolysaccharide-induced liver injury in cirrhotic rats. J Gastroenterol Hepatol. 2004; 19:884-90. | Article | PubMed

24. Antoine M, Tag CG, Wirz W, Borkham-Kamphorst E, Sawitza I, Gressner $\mathrm{AM}$ and Kiefer $\mathrm{P}$. Upregulation of pleiotrophin expression in rat hepatic stellate cells by PDGF and hypoxia: implications for its role in 
Kobuchi et al. Interactive Medicinal Chemistry 2013,

experimental biliary liver fibrogenesis. Biochem Biophys Res Commun. 2005; 337:1153-64. | Article | PubMed

25. Aziz TA, Aziz MA, Fouad HH, Rashed LA, Salama H, Abd-Alla S, Wehab $\mathrm{MA}$ and Ahmed T. Interferon-alpha gene therapy prevents aflatoxin and carbon tetrachloride promoted hepatic carcinogenesis in rats. Int $\mathrm{J} \mathrm{Mol}$ Med. 2005; 15:21-6. | Article | PubMed

26. Rivera-Espinosa L, Muriel P, Ordaz Gallo M, Perez-Urizar J, PalmaAguirre A and Castaneda-Hernandez G. Ketorolac pharmacokinetics in experimental cirrhosis by bile duct ligation in the rat. Ann Hepatol. 2003; 2:175-81. | Article | PubMed

27. Ji H, Jiang JY, Xu Z, Kroeger EA, Lee SS, Liu H, Shen $H$, Zhang M, Minuk GY, Choy PC and Gong Y. Change in lipid profile and impairment of endothelium-dependent relaxation of blood vessels in rats after bile duct ligation. Life Sci. 2003; 73:1253-63. I Article I PubMed

28. Fursule RA and Patil SD. Hepatoprotective and antioxidant activity of Phaseolus trilobus, Ait on bile duct ligation induced liver fibrosis in rats. J Ethnopharmacol. 2010; 129:416-9. | Article I PubMed

29. Christians U, Braun F, Kosian N, Schmidt M, Schiebel HM, Ernst L, Kruse $\mathrm{C}$, Winkler $\mathrm{M}$, Holze I, Linck $\mathrm{A}$ and et al. High performance liquid chromatography/mass spectrometry of FK 506 and its metabolites in blood, bile, and urine of liver grafted patients. Transplant Proc. 1991; 23:2741-4. I PubMed

30. Bastien MC, Leblond F, Pichette V and Villeneuve JP. Differential alteration of cytochrome $\mathbf{P 4 5 0}$ isoenzymes in two experimental models of cirrhosis. Can J Physiol Pharmacol. 2000; 78:912-9. | Article I PubMed

31. Sasa $H$, Hashimoto $Y$, Shimizu $T$ and Inui K. Hepatic extraction of tacrolimus in rats with experimental liver diseases. Biol Pharm Bull. 1998; 21:610-4. | Article | PubMed

32. Houdijk AP, Teerlink T, Bloemers FW, Wesdorp RI and van Leeuwen PA. Gut endotoxin restriction prevents catabolic changes in glutamine metabolism after surgery in the bile duct-ligated rat. Ann Surg. 1997; 225:391-400. | Article | PubMed Abstract | PubMed Full Text

33. Undre NA. Pharmacokinetics of tacrolimus-based combination therapies. Nephrol Dial Transplant. 2003; 18 Suppl 1:i12-5. | Article | PubMed

34. Undre NA, van Hooff J, Christiaans M, Vanrenterghem Y, Donck J, Heeman U, Kohnle M, Zanker B, Land W, Morales JM, Andres A, Schafer A and Stevenson P. Low systemic exposure to tacrolimus correlates with acute rejection. Transplant Proc. 1999; 31:296-8. | Article | PubMed

35. Hyogo H, Tazuma S, Nishioka T, Ochi H, Yamaguchi A, Numata Y, Kanno K, Sakomoto M, Asamoto Y, Tsuboi K, Nakai K, Yasumiba S, Sunami Y and Kajiyama G. Phospholipid alterations in hepatocyte membranes and transporter protein changes in cholestatic rat model. Dig Dis Sci. 2001; 46:2089-97. | Article | PubMed

36. Huang YT, Hsu YC, Chen CJ, Liu CT and Wei YH. Oxidative-stress-related changes in the livers of bile-duct-ligated rats. J Biomed Sci. 2003; 10:170-8. | Article | PubMed

37. Grintzalis K, Papapostolou I, Assimakopoulos SF, Mavrakis A, Faropoulos K, Karageorgos N, Georgiou C, Chroni E and Konstantinou D. Time-related alterations of superoxide radical levels in diverse organs of bile ductligated rats. Free Radic Res. 2009; 43:803-8. | Article I PubMed

38. Kobuchi S, Fukushima K, Aoyama H, Matsuda T, Ito Y, Sugioka N and Takada K. Effect of oxidative stress on the pharmacokinetics of clomipramine in rats treated with ferric-nitrilotriacetate. Drug Metab Lett. 2011; 5:243-52. | Article | PubMed

39. Kobuchi S, Fukushima K, Aoyama H, Ito Y, Sugioka N and Takada K. Effects of oxidative stress on the pharmacokinetics and hepatic metabolism of atazanavir in rats. Free Radic Res. 2013; 47:291-300. I Article I PubMed

40. Kobuchi S, Fukushima K, Ito Y, Sugioka N and Takada K. Pharmacokinetics and distribution of fluvoxamine to the brain in rats under oxidative stress. Free Radic Res. 2012; 46:831-41. | Article | PubMed

41. Sasaki M, Maeda A, Sakamoto K and Fujimura A. Effect of bile acids on absorption of nitrendipine in healthy subjects. Br J Clin Pharmacol. 2001; 52:699-701. | Article | PubMed Abstract | PubMed Full Text

42. Shimomura M, Masuda S, Saito H, Sakamoto S, Uemoto S, Tanaka K, Inui $K$. Roles of the jejunum and ileum in the first-pass effect as absorptive barriers for orally administered tacrolimus. J Surg Res. 2002; 103(2):215-
222. | Article | PubMed

43. Igarashi T, Yano I, Saito H and Inui K. Decreased cyclosporin A concentrations in the absorption phase using microemulsion preconcentrate formulation in rats with cisplatin-induced acute renal failure. Biol Pharm Bull. 2003; 26:1591-5. | Article I PubMed

44. Sauer P, Stiehl A, Fitscher BA, Riedel HD, Benz C, Kloters-Plachky P, Stengelin S, Stremmel W and Kramer W. Downregulation of ileal bile acid absorption in bile-duct-ligated rats. J Hepatol. 2000; 33:2-8. | Article I PubMed

45. Kobayashi M, Takaya S and Koie H. Effect of a stable analogue of prostacyclin on cyclosporine A-induced nephrotoxicity: morphological qualitative and quantitative studies. Transplant Proc. 1988; 20:183-6. PubMed Abstract I PubMed Full Text

46. Furukawa H, Imventarza O, Venkataramanan R, Suzuki M, Zhu Y, Warty VS, Fung J, Todo $S$ and Starzl TE. The effect of bile duct ligation and bile diversion on FK506 pharmacokinetics in dogs. Transplantation. 1992; 53:722-5. | Article | PubMed Abstract | PubMed Full Text

47. Deters M, Klabunde T, Kirchner G, Resch K and Kaever V. Sirolimus/ cyclosporine/tacrolimus interactions on bile flow and biliary excretion of immunosuppressants in a subchronic bile fistula rat model. $\mathrm{Br} \mathrm{J}$ Pharmacol. 2002; 136:604-12. | Article | PubMed Abstract | PubMed Full Text

\section{Citation:}

Kobuchi S, Fukushima K, Maeda Y, Kokuhu T, Ushigome $\mathrm{H}$, Yoshimura N, Sugioka N and Takada K. Effects of bile duct stricture on the pharmacokinetics of the immunosuppressant tacrolimus in rats. Interact Med Chem. 2013; 1:1. http://dx.doi.org/10.7243/2053-7107-1-1 